\title{
Using Images of Farmed Animals in Environmental Advocacy: An Antispeciesist, Strategic Visual Communication Proposal
}

\author{
Laura Fernández*
}

\begin{abstract}
This article discusses two main issues: the historical invisibility of the role of animal agriculture in climate change and whether it is useful to include explicit violent images or "moral shock" of farmed animals ${ }^{1}$ in environmental advocacy campaigns to fight against climate change and environmental devastation. The claim will be explored at two levels: ethical and strategic. According to the current literature available, it will be argued that we have sound arguments to believe that using images of farmed animal suffering (including explicit violent images and moral shocks) is both an ethical and effective approach to reach the end of speciesist oppression and to mitigate climate change.
\end{abstract}

\section{Keywords}

strategic visual communication, advocacy, moral shock, speciesism, climate change, mitigation, farmed animals, vegan diet

Environmental advocacy campaigns are launched across the global geography to reveal the damages humans cause to nature, including images of oceans, forests, and deserts showing water pollution, deforestation, habitat transformation, earth deterioration, or global warming. However, nonhuman animal liberation movements have historically used images of exploited animals to reveal the atrocities of animal agriculture industries to the public opinion. When analyzing environmental campaigns from the animal advocacy perspective, it seems remarkable that environmental organizations have forgotten the impacts of the animal agriculture industry on climate change and environmental devastation (e.g., Leip et al., 2010; Scarborough et al., 2014; Steinfeld et al., 2006). I argue here that, in this omission, environmental advocates have disregarded both the ethical arguments and the potential effectiveness of using images of farmed animals' suffering.

In this article, strategic visual communication in animal liberation and environmental advocacy are addressed with a focus on the impact animal agriculture and aquaculture industries have on climate change. The agribusiness generates more direct human-caused animal deaths and suffering than any other industrial activity (Animal Charity Evaluators, 2016). Yet, despite being one of the central causes of current climate change (de Boer, Schösler, \& Boersema, 2013; Goodland \& Anhang, 2009; Leip et al., 2010; Steinfeld et al., 2006; Worldwatch Institute, 2004), the animal agriculture issue has persistently been suppressed from the campaigns of environmental advocacy organizations. The aim of this article is

\footnotetext{
*Universitat Pompeu Fabra, Barcelona, Spain

Corresponding Author: Laura Fernández, Department of Communication, Universitat Pompeu Fabra, Barcelona, Spain. Email: laura.fernandez@upf.edu / lauferagui@gmail.com

${ }^{1}$ Following Freeman (2014), I have decided to use the term farmed animal instead of farm animal to underline the idea that "farming is something we do to these individuals-something we force upon them" (p. 29).
} 
to find the "common ground" (Kemmerer, 2015) between these two advocacy movements and to examine to what extent they can (or cannot) complement and feed each other from an advocacy point of view.

Animal agriculture and aquaculture industries could be considered as one of the main global factors responsible for anthropogenic-based climate change emissions and the current environmental devastation (de Boer et al., 2013; Goodland \& Anhang, 2009; Leip et al., 2010; Scarborough et al., 2014; Steinfeld et al., 2006; Worldwatch Institute, 2004). At the same time, these industries based their existence on the exploitation of other animals to create economic profit and their practices are absolutely violent, oppressive, and environmentally detrimental. The environmental advocacy movement and the animal advocacy movement have different goals and incompatible theoretical approaches (Faria, 2012), which may lead to different courses of actions in some cases. However, the rejection of animal agriculture and aquaculture, along with the promotion of a vegan diet as a mitigation policy could be considered an interesting nexus for these two movements (Best, 2014; Kemmerer, 2015) in a world where both nonhuman animals and the environment are relegated to a secondary place.

We find ourselves in highly visual social and cultural contexts, where technological expansion has led to greater importance of the visuals for disseminating ideas. In this context of visual overstimulation, advocacy groups are committed to generating effective visual communication to make their messages of social, environmental, and interspecies justice accessible and striking to society as a whole.

In this article, it will be argued that using images of farmed animals is an ethical and strategic tool for raising awareness about both environmental and animal advocacy. Animal liberation movements have historically made use of images of suffering (Aaltola, 2014), whereas environmental advocacy movements are only recently - and timidly_including the links between consumption of animal products and environmental devastation. Nevertheless, this approach "is a very much under-explored option for mitigating climate change" (de Boer et al., 2013, p. 5) and it is an understudied topic from the visual communication field, especially if we talk about incorporating animal suffering into the equation.

Regarding the connection between climate change and meat production and consumption, in 2004, the Worldwatch Institute declared that

per-capita meat consumption has more than doubled in the past half-century, even as global population has continued to increase. As a result, the overall demand for meat has increased five-fold. That, in turn, has put escalating pressure on the availability of water, land, feed, fertilizer, fuel, waste disposal capacity, and most of the other limited resources of the planet. (p. 12)

Laestadius, Neff, Barry, and Frattaroli (2014) have approached the factors influencing nongovernmental organization (NGO) decisions to campaign for reduced meat consumption in light of the climate change. They found that, generally, environmental NGOs have promoted only small changes to meat consumption and they did this in minor ways rather than establishing dedicated campaigns regarding the issue (Laestadius et al., 2014). The main NGOs' arguments for not including dietary choice in their campaigns are as follows: (a) the idea that it is the niche of animal protection organizations or foodfocused NGOs, which also work more on the "the arena of the everyday" in opposition of certain environmental NGOs that are more focused on systemic institutional change (Laestadius et al., 2014, pp. 33-34); (b) that this focus does not fit in with their mission, identity, ideology, or values (Laestadius et al., 2014, p. 33); (c) that this approach differs from their tactical preferences: "most environmental NGOs...expressed a clear preference for policy advocacy, litigation, research, or working to influence corporate practices rather than public education focused on encouraging behavior change" (Laestadius et al., 2014, p. 36); (d) they find advocating against meat eating to be counterproductive (de Boer et al., 2013) because it can be considered paternalistic and alienate NGO supporters-dietary choice is considered a personal individual right in Western cultures (Laestadius et al., 2014) — and they perceive a low outcome of engagement both because of "the challenging and controversial nature of addressing meat consumption through personal behavior, and limited political and public interest in climate change" (Laestadius et al., 2014, p. 36); and (e) the NGOs' capacity and limited resources to take on the issue. 
In contrast, potentialities have been found in addressing animal agriculture and aquaculture and dietary choice from an environmental perspective: "Changing meat-eating habits may be seen as a relatively cheap and easy way to mitigate climate change, in contrast to many other climate mitigation behaviors, which are seriously constrained by external factors" (Whitmarsh \& O'Neill, 2010 in de Boer et al., 2013, p. 5). It has also been argued that

personalizing the roles and fates of individual animals could be a useful complement to consciousness raising about the environmental consequences of animal farming. Nonhuman animals, their destinies and well-being, as they are entwined with human decisions, could be a powerful source of emotional connection with rational arguments for reduction of animal use. (Cole et al., 2009, p. 167)

To this end, in the following article two main issues will be discussed:

The first section will review how the historical invisibility of the role of animal agriculture in climate change discourse is the result of the speciesist bias that is dominant in society. Then, a discussion about strategic visual communication will be introduced. The article will examine whether including explicit violent images or "moral shock" (Jasper \& Poulsen, 1995) of farmed animals in environmental advocacy campaigns should be used to fight against climate change and environmental devastation. The claim will be explored at two levels: ethical and strategic.

At the ethical level, I will analyze the interconnection between animal ethics and a nonspeciesist approach to climate ethics, which considers environmental damages from a global point of view, including human and nonhuman suffering, in particular the suffering of farmed animals and the ethical relevance of representing it in campaigns. This perspective may build bridges between environmental and animal advocacy movements and may be helpful for environmental advocates to raise awareness about the different kinds of violence at play.

At the strategic communication level, I argue that focusing on the suffering of farmed animals, in addition to environmental damages caused by animal agriculture industries, might also be effective for environmental advocacy campaigns. Images of explicit violence and suffering may provide, for both environmental and animal liberation campaigns, a persuasive appeal for action.

Considering the ethical reasons, we have to denounce speciesism and the lessons environmental communication can obtain from animal advocacy campaigns, the representation of farmed animal suffering is positive to (a) consider exploited farmed animals' interests and to denounce speciesism and (b) to fight against environmental degradation and climate inaction through dietary choices.

\section{Suppression and Invisibility of Aquaculture and Animal Agriculture Industries in Environmental Advocacy}

In this section, the omitted connections between environmental defense and the advocacy for farmed animals exploited for food production are explored.

Evidence connecting animal agriculture and aquaculture to environmental damages and climate change is enormous. By analyzing the data, it can be observed that there is a gap in environmental advocacy regarding farmed animals, shown in their exclusion from predominant environmental discourse and practice (Laestadius et al., 2014). This gap is visible, for instance, with the impact of animal agriculture and aquaculture industries on greenhouse gas (GHG) emissions and air pollution, water waste, species extinction, biocontamination, diseases, soil degradation, deforestation, and energy waste, among other problems.

The reason for this exclusion could be the dominance of both the developmentalist paradigm that conceives a world of infinite resources and the speciesist bias in climate ethics and environmental justice, which conceives nonhuman life as inferior to human life, or even as mere resources for human needs. As a consequence, this bias is not only damaging the environment and human animals but it is especially 
harmful for nonhuman animals. In what follows, the consequences of animal agriculture and aquaculture in climate change and environmental devastation will be briefly addressed.

First, animal agriculture, especially factory farming, is directly involved in air pollution. The polluting substances "are released from farmed animal waste stored in manure lagoons, and from the land on which manure is spread or sprayed" (Hunt, 2015, p. 178). Of particular importance among the main air pollutants are GHG. From 14,5\% (FAO, 2014) to 51\% (Goodland \& Anhang, 2009) of annual worldwide GHG emissions are attributable to the animal agriculture industry. Goodland and Anhang's (2009) analysis considers not only methane - a potent global warming gas that is the product of farmed animals' digestion - but also farmed animals' respiration.

Second, animal agriculture and factory farming are also linked with water waste and pollution. Humans are appropriating more than half of the planet's usable, flowing freshwater (Halley, 2015, p. 151). To turn nonhuman animals into consumable goods, farmed animals must first be kept alive, which means that large amounts of food and water must be devoted to the approximately 69.4 billion land farmed animals (Consider Veganism, 2018.) exploited by agribusiness in the world. Focusing only on the water needs of land farmed animals, we can predict the water savings derived from a vegan diet: "Because of the amount of freshwater required for animal agriculture, the average American omnivore 'consumes' 4,200 gallons (15,900 liters) of freshwater per person per day, while an American vegan averages just 300 gallons (1,136 liters) per person, daily" (Schwartz in Kemmerer, 2015, p. 187). Regarding water pollution, the waste produced in factory farms and stored in the manure lagoons impairs water quality (Hunt, 2015, pp. 176-178) and excessive nutrients from the manure are frequently carried into groundwater and surface water, damaging the environment and threatening human and nonhuman animal health alike.

There are also some environmental damages directly related with the growing fish farming industryalso called factory fishing. Aquaculture facilities exist generally in netted-off areas of the open ocean, which increases the risk of biocontamination if the farmed fishes ${ }^{2}$ manage to escape and breed with the wild populations. Furthermore, the confinement of factory fishing gives place to parasite infestations in fishes and, as a consequence, they are treated with chemicals and antibiotics. While these drugs can reduce the spreading of the disease between farmed fishes, they pollute oceans and make the wild populations more vulnerable to disease (Kemmerer \& Dopp, 2015).

Aquaculture and animal agriculture are also generating species extinction, deforestation, and soil degradation. The main cause of species extinction is habitat loss, and habitat loss is the consequence of the conversion of rainforests to cultivated land, both for raising the crops to feed farmed animals and to use that space for grazing animals (Halley, 2015). The production of feed crops-especially monocultures - and overgrazing locate the animal agriculture industry and the consumption of animal products as the primary cause of soil degradation and desertification (Western Watersheds Project, 2010). Regarding aquatic life, the manure runoff and its consequent oceanic dead zones are also killing fishes and generating biodiversity loss. There is also a growing traffic in bushmeat which "is decimating the remaining populations of gorillas, chimpanzees, and other primates that are being killed for their meat" (Worldwatch Institute, 2004, p. 19). Bushmeat and the killing of nonhuman primates are the consequence of a crowded planet where poor populations are increasingly looking for meat in wildlife reserves, not just for their own subsistence but as a part of poaching and black marketing animals that live in nature and their body parts (Worldwatch Institute, 2004).

There is also an important point regarding the food productivity of farmland: A reduction of the land used will be beneficial to the environment and this is also connected with social justice issues with respect to indigenous communities' land (Belcourt, 2015) and food sovereignty (Food Empowerment Project, 2018). In that sense, as Halley states, the statistics make it clear: "The vegan diet requires just 0.662 acres

\footnotetext{
2 "Fishes" is used here as a plural to make the multiple sentient individuals inside the concept of "fish" visible.
} 
of cultivated land, compared to 1.107 acres for the standard Western diet, rich in animal products" (Halley, 2015, p. 157).

Finally, eating animal products also implies a huge energy consumption if we also consider the cycle of growing the grains - including the input of petroleum-based agricultural chemicals, the fuel needed to transport farmed animals to the slaughterhouses and, after they are killed, to transport the resulting products to the markets. Afterward, more energy is consumed to refrigerate and cook the animal flesh or its byproducts (Worldwatch Institute, 2004).

It is apparent that it is not possible anymore to keep dissociating the consumption of animals as food and the environmental implication of that dietary choice. That is why, in Lisa Kemmerer's (2015) words “diet is the most critical decision we make with regard to our environmental footprint - and it is a decision that we make every day, several times a day" (p. 186). Several scholars (e.g., Goodland \& Anhang, 2009; Kemmerer, 2015; Leip et al., 2010; Scarborough et al., 2014) have argued that a diet with animal products - even when they are labeled as "sustainable," "humane," "local," "grass-fed," "organic," "freerange," and/or "cruelty free"-is contributing to "greenhouse gas emissions, water pollution, deforestation, soil damage, freshwater depletion and the destruction of wildlife" (Kemmerer, 2015, pp. 193-194).

In his statistical analysis on the impact of dietary choice, Halley (2005) also found out that a vegan diet is the most environmentally sustainable option. He also underlines that

merely removing meat achieves very little - the whole spectrum of animal products must be reduced if we are to reduce our ecological footprint. This is not surprising because raising farmed animals requires much more land than does raising vegetables, and farmed animals are required if we are to have eggs or dairy products. (p. 157)

In parallel, Kemmerer and Dopp (2015) argue that stopping eating sea flesh is "the only dependable way that consumers can do their part to prevent further decline of sea species, decimation of underwater habitat, degradation of ocean ecosystems, and the suffering and premature death of billions of sea creatures" (p. 169).

In a global context of environmental devastation, the combination of both personal dietary changes and policy changes for industrial regulations should be adopted as an urgent action for climate mitigation to avoid present and long-term environmental harm. However, these changes in animal exploitation industries are difficult to achieve because of the tremendous financial and political power of agribusinesses to protect their interests (Hunt, 2015). The influence that corporate lobbying, think tanks and discourse coalitions promoted by the industry have on the global discourse creation process and on the mediated public sphere is huge, including favoring the elites and maintaining social, environmental, and interspecies inequality (Almiron, 2017a).

As a conclusion, dietary choice has enormous implications on climate change and environmental damage, apart from the suffering it causes both to wild and farmed animals. In addition, it contributes to aggravating social issues such as the global food crisis or farm workers' labor rights. ${ }^{3}$

Therefore, adopting a vegan diet is, all things considered, the most sustainable dietary choice to fight against climate change and environmental degradation. Also, as I discuss below, veganism is not only environmentally friendly but, most importantly, an ethical and political stance on interspecies justice.

\footnotetext{
${ }^{3}$ According to Goodland and Anhang (2009), vegetable products analogous to animal products could also help farm workers to shift toward a more skilled job, as well as creating more jobs and avoiding the "harmful labor practices found in the livestock sector" (2019, p. 19).
} 


\section{The Ethical Bias in Animal Agriculture}

British Donald Watson and Elsie Shrigley, ${ }^{4}$ cofounders of the first vegan society in the world, coined the word "veganism" in 1944. Before the birth of the concept, however, there was already a history of ethical vegetarianism and of opposition to nonhuman animal exploitation and use - as exemplified by Buddhists, Jains, or Pythagoreans - but Watson and Shrigley represented the beginning of veganism as a modern ideology (Almiron, 2017b). Their aim when coining the concept was to distinguish the ethical opposition against the exploitation and abuse of nonhuman animals from other meanings of the previous concept "vegetarianism" (Almiron, 2017b). Later, in 1970, the term "speciesism" was coined by Richard Ryder (2010), and then spread through literature (a prominent example is Peter Singer with the classic Animal liberation, 1975/1990). Speciesism has been defined in a moral sense as "the unjustified disadvantageous consideration or treatment of those who are not classified as belonging to a certain species" (Horta, 2010). Speciesism had also been analyzed from a structural point of view (Nibert, 2002), it is a system of oppression which is inextricably connected with other systems of domination such as heteropatriarchy and sexism (Adams, 1990/2010; jones, 2014), colonialism and racism (Belcourt, 2015; Nibert, 2002), ableism (Fantaske, 2013), capitalism and classicism (Hribal, 2010; Nibert, 2002), and earth domination (Best, 2014; Kemmerer, 2015).

In a context where speciesism is strongly normalized, the hegemonic representations of nonhuman animals are characterized by the speciesist ideology (e.g., Khazaal \& Almiron, 2016; Nibert, 2002), which is based on human supremacy, the instrumentalization of other animals, the reproduction of the human/animal binary and the distorted representation of nonhuman animals and their relations with humans. Nonhuman animals' sentience and complex emotional lives (Bekoff, 2007) have remained generally unnoticed, ignored and distorted under the speciesist gaze. The way we refer to nonhuman animals and their lives also reproduces their inferiorization (Stibbe, 2012). In the environmental approach to farmed animals, the speciesist bias is frequently reproduced and the "animal standpoint" (Best, 2014) is ignored. As stated by Best (2014),

the animal standpoint seeks generally to illuminate human biological and social evolution in important new ways, such as revealing the origins, dynamics, and development of dominator cultures, social hierarchies, economic and political inequalities, and asymmetrical systems of power [ . . ] Providing perspectives and insights unattainable through other historical approaches, the animal standpoint analyzes how the domination of human over nonhuman animals is intimately linked to the domination of humans over one another, as it also brings to light the environmental impact of large-scale animal slaughter and exploitation. (p. 22)

\section{Ethical Reasons for Including Farmed Animals in Environmental Advocacy}

Climate change and environmental devastation affect not only human populations but also nonhuman animals living in nature and those who are exploited by humans. These impacts are mostly due to anthropogenic causes, which consequently make us humans responsible for mitigating climate change and, correspondingly, stopping hurting other animals for our purposes. ${ }^{5}$

Animal agriculture and aquaculture are known for being not only unnecessary and environmentally detrimental practices but ethically indefensible. Billions of chickens, hens, pigs, cows, calves, turkeys,

\footnotetext{
${ }^{4}$ Elsie Shrigley has been erased from the history of veganism, as happened with a lot of women in social justice movements whose voices have been forgotten or silenced as a result of the patriarchy and the androcentric bias. More information is available at http:// www.collectivelyfree.org/elsie-shrigley/

${ }^{5}$ Environmental damages caused by anthropogenic causes are not the only ones affecting nonhuman animals living in nature. If we take an antispeciesist stand, we should also work to prevent and avoid animal suffering in nature, regardless of the anthropogenic or nonanthropogenic origin of it (e.g., Faria, 2012).
} 
sheep, horses, and rabbits are born each year to become food for humans. Others, such as creatures of the sea-who "lack the fuzzy bodies that tend to attract human empathy" (Kemmerer \& Dopp, 2015, p. 163)_or some insects, such as bees, are also suffering in this precise moment in factory, mixed or extensive farms. Their future, anyway, is similar: they are raised, generally caged, exploited, fattened up, and finally killed. Often, the stunning process with electric shocks, electrics baths, suffocation, manual disgorgement, or captive bolts is not properly applied, and the animals are conscious when they are being killed. Farmed animals are always killed without living their whole expected life span; for example, while chickens could live between 10 and 15 years, they are killed in the first 21 days of life. In addition, human selection and animal transgenesis ${ }^{6}$ have worked hard to make exploitation as profitable as possible: for example, they have raised races, such as the broiler chicken, which grow rapidly in a shorter period of time. These chickens suffer a lot from injuries and lesions in their legs because they cannot support their own weight.

During this process, farmed animals' individuality and unique personality disappear in front of the enormous speciesist structure, which only considers farmed animals as commodities. However, before becoming flesh, before being valued for their eggs, dairy, or honey, those animals had a life and, therefore, an interest in, being alive, avoiding suffering and enjoying freedom, rights which they have been denied by the industries exploiting nonhuman animals with the support of the manufactured consent of society (Almiron, Cole, \& Freeman, 2018).

As we have already seen, the use of nonhuman animals, and in particular of farmed animals, is collaterally prejudicial to humans and the environment too, such as by the unequal distribution of resources and the damages toward free-living animals and the environment. Speciesism and meat eating have been connected with other oppressions: the exercise of violence toward nonhuman animals is psychologically related to that of violence toward human animals, with the mistreatment and abuse of nonhuman animals being a predictive symptom of future violent acts toward human animals (National Sheriffs' Association, 2018). Feminized and nonhuman bodies are involved in patriarchal cultural processes by which they are objectified, fragmented, and then - symbolically or literally — consumed, when the referent—whether a feminized body or a nonhuman animal—disappears (Adams, 1990/2010). There is an inextricable link between heteropatriarchal domination, earth domination, and domination toward nonhuman animals which is based on the Western binary thinking structure. This structure of thought organizes the world into categories such as human/animal, man/woman, culture/nature, $\mathrm{mind} /$ body, reason/emotion, in which the first ones are privileged over the second ones. It is noticeable, for example, by the animalization of other oppressed individuals (racialized people, queer people, or people with disabilities, among others) as a way of perpetuating the belief in their lower moral consideration and not assigning them the full "human status" (as shown, e.g., by Adams, 1990/2010; Fantaske, 2013; jones, 2014; Kemmerer, 2015; Ko \& Ko, 2017).

Effective advocacy uses the best available evidence to discover the best ways of producing changes in favor of social, environmental, and interspecies justice. Following Fisher (2017), effective animal advocacy aims to "choose from available interventions so that advocates do the most good they can for animals" (p. 2). To achieve that goal, it has been argued that images of animal suffering play a very relevant role for effective animal advocacy, both as "a form of normative rhetoric and a method of persuasion" (Aaltola, 2014, p. 19). The visual discourse is much more connected to the emotion and emotions are vital for social movements "to attract new recruits, sustain the commitment and the discipline of those already in the movement and persuade outsiders" (Jasper, 2011, p. 292). Emotional visual appeal can, therefore, promote a critical reflection on culturally assumed beliefs and even motivate

\footnotetext{
${ }^{6}$ The Federation of European Laboratory Animal Associations defines the term as "an animal in which there has been a deliberate modification of its genome, the genetic makeup of an organism responsible for inherited characteristics" (FELASA, Federation of European Laboratory Animal Science Associations September 1982, Transgenic Animals-Derivation, Welfare, Use and Protection). The main goals of animal transgenesis are specific economic traits or production of nonhuman animals as disease models. More information is available at http://www.actionbioscience.org/biotechnology/margawati. html
} 
attitude-changes, because of the strong association between morality and emotions (Wisneski \& Skitka, 2017).

Considering not only the moral status of nonhuman animals but also the interrelated character of oppressions, an ethical environmental advocacy approach requires the inclusion of farmed animals. Farmed animals' lives are important and their suffering deserves to be represented to counteract the distorted hegemonic representations of them (based on the aforementioned speciesist ideology). It is also very important to characterize the consequences of environmental devastation-GHG emissions, air pollution, water waste, species extinction, biocontamination, diseases, soil degradation, deforestation, and energy waste, among others-from a nonspeciesist point of view.

The representation of farmed animal suffering, as well as an ethical commitment against species oppression, has been theorized as an effective communication tool by the animal liberation movement (Freeman, 2014), one from which the environmental movement - as long as it is critical with the speciesist bias - can tremendously benefit. Therefore, environmental advocates should reject the speciesist bias so as to take into account the consequences of climate change and environmental devastation on nonhuman animals.

It follows from the above that if environmental campaigns seek to create more ethical communication campaigns, then environmental advocacy should take a nonspeciesist approach toward nonhuman animals in general, and more particularly toward farmed animals, in their visual representations of climate change and environmental devastation. This is so (a) because of the ways systems of oppression overlap with one another, hence the need to move toward a total liberation approach in oppressions (Best, 2014); (b) because of the contribution of animal exploitation to environmental devastation; and (c) because of the fact that we live in a visual era where images have great power. The enormous dimensions of farmed animals' suffering and exploitation should be included in the visual advocacy representations of environmental, social, and interspecies justice.

\section{Strategic Reasons for Including Images of Farmed Animals' Suffering in Environmental Advocacy}

In this section, it will be argued that environmental advocates should reject the speciesist bias so as to acknowledge how animal exploitation contributes to climate change and environmental devastation and thus propose veganism as an effective way of reaching their goals. They should also include visual representations of farmed animal suffering in their discourse as an effective way of reaching their goals. These statements will be based on three main ideas: (a) because of the effectiveness of making visible a concrete strategy of climate change mitigation through dietary choice and the adoption of a vegan diet considering the variables of salience and efficacy, (b) because of the historical role of emotion in attitudechange, and (c) because the effectiveness of using images of free-living nonhuman animals had already been demonstrated (Huddy \& Gunnthorsdottir, 2000; O’Neill, Boykoff, Niemeyer, \& Day, 2013; Swim $\&$ Bloodhart, 2015), and the same approach may work in the case of farmed animals.

\section{A Vegan Diet as a Concrete Mitigation Strategy}

Environmental visual communication scholars take into account two main variables when analyzing images for raising awareness about climate change and environmental issues and to promote people's attitude-change toward climate change mitigation actions: salience and efficacy. Salience, in this case, is the consideration of climate change and environmental devastation as an important issue while efficacy is "a sense of being able to do something about climate change" (O'Neill et al., 2013, p. 414).

According to the literature, climate change and environmental issues - with few time frame exceptionsare underreported by the media (Boykoff \& Smith, 2010). In addition, when these issues are covered, they are framed from an anthropocentric perspective (Almiron \& Zoppeddu, 2015). According to O’Neill 
et al. (2013), climate change is framed in the United States, the United Kingdon, and Australian media in two main different ways: (a) climate change as contested and politized, frequently along with personalization of political figures, business leaders, and scientists and (b) climate change as distant in time and space in both its causes and impacts. These two frames are not good for promoting the selfefficacy ${ }^{7}$ of the climate change issue, and the authors suggest the importance of creating new frames that promote social engagement, including those related with food production and consumption (O'Neill et al., 2013).

From this research, it follows that the strategy of farmed animal suffering, combined with veganism as a dietary choice mitigation policy, might be a useful frame to optimize both salience and efficacy. Regarding salience, the suffering of farmed animals is happening at this moment, it is not necessary to think about terrible futures, but about sentient individuals who are suffering right now, and whose suffering is inextricably connected with the future suffering of other-human and nonhuman — animals and environmental devastation. The suffering frame has a very good emotional appeal to fight climate inaction-it has been shown that

pictures of people or animals [...] have an affective dimension, eliciting an emotional reaction which is perhaps more likely to initiate a thought process or feelings that the issue is salient and worth doing something about. (Nicholson-Cole, 2005, p. 267)

On the other hand, the idea of a vegan diet as a mitigation policy is a very good frame for efficacy, because it is a daily, acceptable and concrete action related with production and consumption that the audiences can do to oppose climate change. These concrete politics are indispensable to increase efficacy when framing the environmental issue (O’Neill et al., 2013).

O'Neill et al. (2013) underline the following key findings on the implications of climate communication:

It seems imagery can play a role in either increasing the sense of importance of the issue of climate change (saliency), or in promoting feelings of being able to do something about climate change (efficacy) — but few, if any, images seem to do both. Communication strategies should assess the purpose of their message, and choose to employ images accordingly. (p. 420)

In that sense, as efficacy and salience are not easily included in the same image, the combination of the suffering frame with the dietary choice frame promoting a vegan diet might be a strategic approach from a nonspeciesist environmental advocacy. ${ }^{8}$

\section{Moral Shocks, Explicit Violence, and the Role of Emotion for Attitude-Change}

Nicholson-Cole (2005), in her article "Representing climate change futures: a critique on the use of images for visual communication" refers to the set of typologies presented by Lorenzoni and Langford (2001) based on a study of public perceptions of climate change. The four broad groups of people they classify are termed the "deniers," the "disinterested," the "doubters," and the "engaged." For the environmental movement - as for other social movements - the aim would be to move as many people as possible toward the "engaged" group. As seen before, images are a fundamental tool for this goal. Even if we still need more research to find out what kinds of visuals are more effective to raise awareness on environmental, interspecies, and social justice issues and to motivate attitude-change, the existing evidence points to the fact that emotional appeal has serious potential in the field of advocacy communication.

\footnotetext{
${ }^{7}$ O'Neill et al. (2013) use the concept of self-efficacy referring to the individual dimension of efficacy. From now on I will prioritize the shortened term "efficacy."

${ }^{8}$ From the animal liberation point of view, this frame combination is also strategic for the audiences to raise awareness about their own "cognitive dissonance" - the inharmonic state between individual values and actions (Joy, 2010) - in their relations to farmed animals, and to return the visibility to the animal individual — the "absent referent" in Adams' (1990/2010) wordsbehind the flesh or the animal product.
} 
Emotions and emotional appeals have been understood as interferences with rationality (Jasper, 1998) or as a bias for cognition (Huddy \& Gunnthorsdottir, 2000). To the contrary, what social psychology shows is that affect and cognition work more as an integrated model than mere opposites (Huddy \& Gunnthorsdottir, 2000).

It follows then, the environmental advocacy movement can benefit from the persuasive effects of including emotions as a central issue in its communication strategies. In this respect, while approaching emotions in visuals, it is relevant not to forget that: "Human beings do not just passively receive new information. On the contrary, they actively fit that information into preexisting cultural models and concepts" (Kempton, 1997, p. 20). Cultural norms shape what will be labeled as normal or deviant and sustain different cultural backgrounds of shared assumptions (Jasper, 1998; Jasper \& Poulsen, 1995). What seems most effective for the moment is to run different communication campaigns aimed at concrete audiences, because effectiveness is far from being universal, but strongly conditioned by power relations and social structure-changing with the audience's gender, class, race, age, level of studies, nationality, and so on.

Within the animal movement, controversy is high regarding the use and effectiveness of explicit violent images of animal suffering, also called "moral shocks." The discussion revolves around the potential capacity of emotional impacts to generate engagement and awareness (salience) or backlash and demobilization (efficacy; O’Neill et al., 2013).

Moral shock has been described by the coiners of the term as a stimulus that causes a sense of outrage which in turn leads individuals to react in response to it (Jasper \& Poulsen, 1995). Following Jasper and Nelkin (2007), moral shocks have been used as a recruiting tool for protest movements because of their persuasive nature, even on people with no prior political interest. Scudder and Mills (2009) studied a PETA's antifactory farming shock advocacy campaign and its credibility among university students. The main conclusion was that PETA gained credibility, while the meat industry lost it: the moral shock visuals generated negative predisposition toward factory farming. The results of this research are the precise opposite of Mika's (2006) previous study on PETA's communication strategies, which concluded that moral shocks may alienate a portion of the audience by generating offense and a loss of credibility of the whole animal movement.

Other studies are similarly contradictory. For instance, on one hand, Wisneski and Skitka (2017) hold that moral shocks are connected with morality, as they "appear to moralize attitudes without affecting other dimensions of attitude strength" (p. 147).

The authors, however, suggest "moral shocks require the activation of attitudinally relevant disgust and conscious awareness of the source of that disgust" (pp. 147-148). In that sense, those who are more committed to the environmental or animal cause "are influenced the most about emotive appeals" inciting them to action, as Huddy and Gunnthorsdottir (2000) already stated two decades ago (pp. 766-767).

On the other hand, other researchers conclude that moral shock strategies have the risk of desensitizing or paralyzing instead of engaging (Mika, 2006; Sullivan \& Longnecker, 2010). From an ethical point of view, moral shocks of farmed animal suffering can perpetuate an objectified representation of their bodies and prevent the viewer from morally recognizing and challenging the speciesist violence (Aaltola, 2014; Atlas, 2014) as well as contributing to "compassionate fatigue" among activists and certain audiences (Aaltola, 2014).

Considering the above evidence, it can be concluded that images of the suffering of farmed animals in general, and moral shock and images of explicit violence in particular, have been effective for attitudechange at least in some cases in the past. However, it is important to point out the concomitant risks

\footnotetext{
${ }^{9}$ Philosopher Elisa Aaltola (2014) defined compassionate fatigue as "the wearing out of the ability to care about suffering" (p. 28).
} 
involved in the use of these types of visuals: the denial of nonhuman animal agency (Atlas, 2014) and the contribution to the violation of nonhuman animals' privacy (Aaltola, 2014), as well as the problem of the compassionate fatigue between certain audiences, especially the activist ones (Aaltola, 2014). To minimize those risks, nonhuman animals' suffering should be represented in a context where they can be morally recognized as sentient individuals (Aaltola, 2014; Atlas, 2014), as well as beings who resist oppression (Atlas, 2014; Hribal, 2010). To fill the gap between salience and efficacy and avoid, as far as, possible compassionate fatigue, "extreme images ought to be accompanied by efforts to invite action and optimism that something can, indeed, be done" (Aaltola, 2014, p. 28).

Producing moral shocks by means of showing the suffering of farmed animals may be an effective way to visually engage society on both environmental and animal advocacy, as we have seen both struggles may often coincide. Images of farmed animal suffering could — and should — also be combined with other visual approaches - for example, digital visualization ${ }^{10}$ (Nicholson-Cole, 2005) — and ethical-political discourses that bring a deeper explanation of what the images are depicting.

\section{Breaking the Species Barrier to Represent Farmed Individuals}

Nonhuman animals have historically been part of environmental campaigns. It is difficult to think about the melting of the polar ice caps without the widespread images of starving polar bears as a direct consequence of anthropogenic-induced climate change (Swim \& Bloodhart, 2015).

These images, mainly of animals living in nature or of species in danger of extinction, have favored an emotional approach to environmental issues. This brings to the forefront the challenge by the animal movement of "breaking the species barrier," which invites us to think critically about the nonanthropocentric speciesism and the differential consideration we give to some species and deny to others. The available (even though insufficient) data points to the fact that emotional appeals triggered by the images of free-living animals can be replicated by using images of farmed animals to denounce their terrible exploitation and its terrible effects on the environment. However, this communication strategy might benefit both the environmental and the animal advocacy movements.

For instance, Huddy and Gunnthorsdottir (2000) hold that "the environmental movement has some of the most powerfully affecting images at its disposal-cute animals that provoke almost universally positive emotions" (p. 768). The capacity humans have to connect with other animals through visual communication might have positive consequences for oppressed animals and the environment. The environmental advocacy movement might strategically use the emotional appeal of images depicting the suffering of nonhuman individuals in farms while framing them as sentient beings with complex emotional lives.

Additionally, it is necessary to be cautious with the use of cute and positive images of rescued farmed animals and always tell their unique personal story (Atlas, 2014) and frame them in a realistic way, because they represent a tiny fraction of nonhuman animals' reality which, on the contrary, is full of oppression, pain, and suffering. The differences between species and how such differences would vary what level of explicit violence is more effective to motivate attitude-change toward a vegan diet and an antispeciesist stand is also an under researched issue that should be addressed in future approaches to the topic.

As already stated, focusing on the suffering of individual farmed animals in addition to the environmental damages caused by animal agriculture and aquaculture industries may be relevant to increase the effectiveness of visual communication strategies. Environmental and animal liberation campaigns may find a persuasive appeal to action in images of violence and suffering that is positive both to consider exploited farmed animals' interests while denouncing speciesism and to fight against climate inaction through a change in dietary choices.

\footnotetext{
${ }^{10}$ Digital visualization is understood here as the creation of digital-produced visuals of climate change to motivate and engage people with the issue.
} 


\section{Discussion}

\section{Using the Suffering of Farmed Animals to Overcome Speciesism and the Global Climate Change Crisis}

The environmental and animal movements have radically different priorities: the ecosystems balance the former and the well-being of nonhuman individuals the latter. At the same time, they are strongly connected by the common aim of improving the world from a nonanthropocentric perspective. This article is a call to focus on this common ground, to learn and be nourished by the other's strategies and approaches and to jointly oppose common enemies for both the earth and nonhuman animals by means of strategic visual communication. The best example of this connection is the case of the animal agriculture and aquaculture industries and the immensely negative impact they have on farmed animals, wild animals, and the whole planet, as well as their negative effects on social justice for human animals.

In this article, it has been suggested that we have sound reasons to believe that using images depicting the suffering of farmed animal, and particularly including explicit violent images to trigger moral shocks, is both an ethical and effective approach to advance toward the end of both the speciesist oppression and the mitigation of climate change. Images of suffering are a persuasive appeal, which emotionally connect the audiences with the reality and moralize attitudes, motivating the process of attitude and behavioral change. At the same time, these images increase the salience and efficacy of animal and environmental advocacy issues by promoting concrete changes such as a vegan diet to contribute to a better world while leaving demobilizing feelings apart.

The consideration of the animal standpoint and the promotion of an ethical approach to nonhuman animals in environmental visual communication is a huge opportunity to build bridges between movements to overcome the speciesist system of domination that is at the root of the global climate change crisis. The images of suffering of farmed animals might make people wake up to the idea that there is still a lot to do regarding our relations with other animals and the earth. However, what is equally important is that those images can also send us the message that we can, indeed, do something to change these huge problems. The hope for a different world is waiting with excitement to be visually represented.

\section{Author's Note}

A previous version of this article was presented at the Human-Animal Studies Conference ( $U n$ ) Common Worlds in Turku, Finland, held on August 7-9, 2018.

\section{Declaration of Conflicting Interests}

The author declared no potential conflicts of interest with respect to the research, authorship, and/or publication of this article.

\section{Funding}

The author disclosed receipt of the following financial support for the research, authorship, and/ or publication of this article: The research for this article has been conducted with the support of Generalitat de Catalunya (Department of Universities and Research) and the Social European Fund. 


\section{References}

Aaltola, E. (2014). Animal suffering: Representations and the act of looking. Anthrozoös, 27(1), 19-31.

Adams, C. J. (2010). The sexual politics of meat: A feminist-vegetarian critical theory. New York, NY: Continuum. (Original work published 1990)

Almiron, N. (2017a). Favoring the elites: Think-tanks and discourse coalitions. International Journal of Communication, 11, 4350-4369.

Almiron, N. (2017b, January 26). Veganos, mucho más que un estilo de vida [Vegans, much more than a lifestyle]. El Periódico. Retrieved from https://www.elperiodico.com/es/opinion /20170126/veganos-mucho-mas-que-un-estuilo-de-vida-articulo-almiron-5767834

Almiron, N., Cole, M., \& Freeman, C. P. (2018). Critical animal and media studies: Expanding the understanding of oppression in communication research. European Journal of Communication, 33, 367-380.

Almiron, N., \& Zoppeddu, M. (2015). Eating meat and climate change: The media blind spot— A study of Spanish and Italian press coverage. Environmental Communication, 9, 307-325.

Animal Charity Evaluators. (2016). Why farmed animals? Retrieved from https://animalcharityevaluators.org/donation-advice/why-farmed-animals/

Atlas, K. (2014, October 28). Allies and images: The importance of communicating the victim's personhood. The Liberationist. Retrieved from https://www.directactioneverywhere .com/theliberationist/2014/10/28/allies-and-images-the-importance-of-communicating －thevictims-personhood

Bekoff, M. (2007). The emotional lives of animals. Novato, CA: New World Library.

Belcourt, B. R. (2015). Animal bodies, colonial subjects: (Re)locating animality in decolonial

thought. Societies, 5(1), 1-11.

Best, S. (2014). The politics of total liberation. New York, NY: Palgrave Macmillan.

Boykoff, M., \& Smith, J. (2010). Media presentations of climate change. In C. Lever-Tracy (Ed.), Routledge handbook of climate change and society (pp. 210-218). Abingdon, England: Routledge.

Cole, M., Miele, M., Hines, P., Zokaei, K., Evans, B., \& Beale, J. (2009). Animal foods and climate change: Shadowing eating practices. International Journal of Consumer Studies, 33, 162-167.

Consider Veganism. (2018). Animal kill counter. Retrieved from http://considerveganism.com/counter/

de Boer, J., Schösler, H., \& Boersema, J. J. (2013). Climate change and meat eating: An inconvenient couple? Journal of Environmental Psychology, 33, 1-8.

Fantaske, M. (2013, October 28). On intersections between ableism and speciesism [Video file]. Retrieved from https://www.youtube.com/watch?v=6gGC2Z93xXk

FAO (2014). Tackling climate change through livestock. Retrieved from: http://www.fao.org/ag/againfo/resources/en/publications/tackling_climate_change/index.htm

Faria, C. (2012, November). Muerte entre las flores: el conflicto entre el ecologismo y la defensa de los animales no humanos [Death among the flowers: the conflict between environmentalism and the defense of nonhuman animals]. Viento Sur, 125, 67-76.

Fisher, A. (2017). Theory-neutral arguments for "effective animal advocacy." Essays in Philosophy, 18(1), 1-14. 
Food Empowerment Project. (2018). Food justice: Know the issues. Retrieved from http://www.foodispower.org/\#

Freeman, C. P. (2014). Framing farming: Communication strategies for animal rights. New York, NY: Rodopi.

Goodland, R., \& Anhang, J. (2009). Livestock and climate change: What if the key actors in climate change are cows, pigs, and chickens? Retrieved from http://www.worldwatch.org/files/pdf/Livestock\%20and\%20Climate\%20Change.pdf

Halley, J. M. (2015). So you want to stop devouring ecosystems? Do the math! In L. Kemmerer (Ed.), Animals and the environment (pp. 151-162). New York, NY: Routledge.

Horta, O. (2010). What is speciesism? Journal of Agricultural \& Environmental Ethics, 23, 243-266. Retrieved from https://www.researchgate.net/publication/225191816_What_Is_Speciesism

Hribal, J. (2010). Fear of the animal planet: The hidden history of animal resistance. Chico, CA: AK Press.

Huddy, L., \& Gunnthorsdottir, A. H. (2000). The persuasive effects of emotive visual imagery: Superficial manipulation or the product of passionate reason? Political Psychology, 21, 745-778.

Hunt, C. (2015). Farm gone factory: Industrial animal agriculture, animal welfare and the environment. In L. Kemmerer (Ed.), Animals and the environment (pp. 173-185). New York, NY: Routledge.

Jasper, J. M. (1998). The emotions of protest: Affective and reactive emotions in and around social movements. Sociological Forum, 13, 397-424.

Jasper, J. M. (2011). Emotions and social movements: Twenty years of theory and research. Annual Review of Sociology, 37, 285-303.

Jasper, J. M., \& Nelkin, D. (2007). The animal rights crusade. In J. M. Henslin (Ed.), Life in society: Readings to accompany sociology, a down-to-earth approach (pp. 225-232). Boston, MA: Allyn \& Bacon.

Jasper, J. M., \& Poulsen, J. D. (1995). Recruiting strangers and friends: Moral shocks and social networks in animal rights and anti-nuclear protests. Social Problems, 42, 493-512.

jones, p. (2014). The oxen at the intersection: A collision. New York, NY: Lantern.

Joy, M. (2010). Why we love dogs, eat pigs, and wear cows. San Francisco, CA: Conari Press.

Kemmerer, L. (2015). Eating ecosystems. In L. Kemmerer (Ed.), Animals and the environment (pp. 186197). New York, NY: Routledge.

Kemmerer, L., \& Dopp, B. (2015). A fishy business. In L. Kemmerer (Ed.), Animals and the environment (pp. 163-172). New York, NY: Routledge.

Kempton, W. (1997). How the public views climate change. Environment: Science and Policy for Sustainable Development, 39(9), 12-21.

Khazaal, N., \& Almiron, N. (2016). An angry cow is not a good eating experience. Journalism Studies, 17, 374-391.

Ko, A., \& Ko, S. (2017). Aphro-ism: Essays on pop culture, feminism and black veganism from two sisters. New York, NY: Lantern.

Laestadius, L. I., Neff, R. A., Barry, C. L., \& Frattaroli, S. (2014). "We don't tell people what to do": An examination of the factors influencing NGO decisions to campaign for reduced meat consumption in light of climate change. Global Environmental Change, 29, 32-40. 
Leip, A., Weiss, F., Wassenaar, T., Perez, I., Fellmann, T., Loudjani, P., Biala, K. (2010). Evaluation of the livestock sector's contribution to the EU greenhouse gas emissions (GGELS): Final report. Retrieved from https://ec.europa.eu/agriculture/external-studies/livestock-gas_en

Lorenzoni, I., \& Langford, I. (2001). Climate change now and in the future: a mixed methodological study of public perceptions in Norwich (UK). CSERGE Working Paper ECM 01-05. Norwich: CSERGE.

Mika, N. (2006). Framing the issue: Religion, secular ethics and the case of animal rights mobilization. Social Forces, 85, 915-941.

National Sheriffs' Association. (2018). Animal cruelty as a gateway crime. Washington, DC: Office of Community Oriented Policing Services.

Nibert, D. A. (2002). Animal rights, human rights. Lanham, MD: Rowman \& Littlefield.

Nicholson-Cole, S. A. (2005). Representing climate change futures: A critique on the use of images for visual communications. Computers, Environment and Urban Systems, 29, 255-273.

O’Neill, S. J. (2013). Image matters: Climate change imagery in US, UK and Australian newspapers. Geoforum, 49, 10-19.

O’Neill, S. J., Boykoff, M., Niemeyer, S., \& Day, S. A. (2013). On the use of imagery for climate change engagement. Global Environmental Change, 23, 412-421.

Ryder, R. (2010). Speciesism again: The original leaflet. Critical Society, Spring (2). Retrieved from http://www.veganzetta.org/wp-content/uploads/2013/02/Speciesism-Again-the-original-leafletRichard-Ryder.pdf

Scarborough, P., Appleby, P. N., Mizdrak, A., Briggs, A. D. M., Travis, R. C., Bradbury, K. E., \& Key, T. J. (2014). Dietary greenhouse gas emissions of meat-eaters, fish-eaters, vegetarians and vegans in the UK. Climatic Change, 125, 179-192.

Scudder, J. N., \& Mills, C. B. (2009). The credibility of shock advocacy: Animal rights attack messages. Public Relations Review, 35, 162-164.

Singer, P. (1990). Animal liberation: A new ethics for our treatment of animals. New York, NY: Random House. (Original work published 1975)

Steinfeld, H., Gerber, P., Wassenaar, T., Castel, V., Rosales, M., \& de Haan, C. (2006). Livestock's long shadow: Environmental issues and options. Retrieved from http://www. fao.org/docrep/010/a0701e/a0701e.pdf

Stibbe, A. (2012). Animals erased: Discourse, ecology, and reconnection with the natural world. Middletown, CT: Wesleyan University Press.

Sullivan, N., \& Longnecker, N. (2010). Choosing effective frames to communicate animal welfare issues. In 11th International Conference on Public Communication of Science and Technology (PCST) in New Delhi, India (pp. 146-150). Retrieved from https://pcst.co/ archive/pdf/Sullivan_Longnecker_PCST2010.pdf

Swim, J. K., \& Bloodhart, B. (2015). Portraying the perils to polar bears: The role of empathic and objective perspective-taking toward animals in climate change communication. Environmental Communication, 9, 446-468.

Western Watersheds Project. (2010). Public lands ranching: The ecological costs of public lands ranching. Retrieved from https://www.westernwatersheds.org/public-lands-ranch- ing/

Wisneski, D. C., \& Skitka, L. J. (2017). Moralization through moral shock: Exploring emotional antecedents to moral conviction. Personality and Social Psychology Bulletin, 43, 139-150. 
Worldwatch Institute. (2004). Is meat sustainable? Retrieved from http://www.worldwatch.org/node/549

\section{Author Biography}

Laura Fernández is a PhD student in the Department of Communication at Pompeu Fabra University (Spain). Her topic of research addresses visual communication, advocacy, and animal liberation. She is a research fellow at CRITICC research group. 